\title{
Protein patterns of black fungi under simulated Mars-like conditions
}

\section{SUBJECT AREAS: \\ MICROBIOLOGY \\ ECOLOGY}

Received

16 October 2013

Accepted

14 May 2014

Published

29 May 2014

Correspondence and requests for materials should be addressed to K.S. (katja.sterflinger@ boku.ac.at)

\author{
Kristina Zakharova' ', Gorji Marzban' ${ }^{\text {, Jean-Pierre de Vera }}{ }^{2}$, Andreas Lorek ${ }^{2}$ \& Katja Sterflinger ${ }^{1}$
}

\author{
'University of Natural Resources and Life Sciences, Department of Biotechnology, Muthgasse 18, A - 1190 Vienna, Austria, \\ ${ }^{2}$ German Aerospace Center, Institute of Planetary Research, Rutherfordstrasse 2, D-12489 Berlin, Germany.
}

Two species of microcolonial fungi - Cryomyces antarcticus and Knufia perforans - and a species of black yeasts-Exophiala jeanselmei - were exposed to thermo-physical Mars-like conditions in the simulation chamber of the German Aerospace Center. In this study the alterations at the protein expression level from various fungi species under Mars-like conditions were analyzed for the first time using 2D gel electrophoresis. Despite of the expectations, the fungi did not express any additional proteins under Mars simulation that could be interpreted as stress induced HSPs. However, up-regulation of some proteins and significant decreasing of protein number were detected within the first 24 hours of the treatment. After 4 and 7 days of the experiment protein spot number was increased again and the protein patterns resemble the protein patterns of biomass from normal conditions. It indicates the recovery of the metabolic activity under Martian environmental conditions after one week of exposure.

A

strobiology is in the focus of many scientific investigations, trying to answer questions about the possible existence of life on other planets, survival in outer space and possible interplanetary transfers. Organisms which inhabit extreme environments - the so-called extremophiles - are generally considered to be the best model for exobiological studies ${ }^{1}$. Extremophiles can not only survive extreme thermo-physical conditions, but can also tolerate extreme saline, acidic, alkaline or other conditions which can induce DNA damage in less resistant organisms ${ }^{2-5}$.

Earth's biosphere has evolved in more than 3 billion years while protected by the planet's magnetosphere and the atmosphere from the hostile environment of outer space. The conditions of outer space like space vacuum, thermal extremes, cold, solar UV radiation, ionizing radiation and galactic radiation are real challenges for any form of life ${ }^{6}$. Fungi in general and especially melanized ones showed high resistance when were exposed to ionizing radiation ${ }^{7,8}$. Large quantities of highly melanized spores have been found in early Cretaceous period deposits when many species of animals and plants become extinct. This period matches with Earth's crossing the 'magnetic zero event' when the planet lost its protection against cosmic radiation'.

Martian climate conditions are too cold and the atmosphere too thin for allowing bulk water to be stable. However, at environmental conditions similar to Mars-like conditions the metabolic activity has been detected in presence of one or two monolayers of water, which was proved by laboratory experiments ${ }^{10}$. A precondition for habitability on Mars would be the water availability and interaction between regolith and near-surface atmosphere $^{11}$. Some investigations were performed on organisms which might have a certain potential to live on Mars ${ }^{1,4,12,13}$. Albeit organisms need water activities of $\mathrm{a}_{\mathrm{w}}=0.8-0.9$ for active metabolism, there are some special life forms which are also able to live in much drier conditions with a temporary saturation of atmospheric water vapor, for instance black microcolonial fungi (MCF) and some lichens. Such temporary saturation can occur on Mars ${ }^{4,14,15}$ as it is known by recent studies some extremophilic organisms are able to cope successfully with Marslike conditions. For instance, it was reported that the vitality and photosynthetic activity of lichens is maintained under Mars-like conditions ${ }^{4,14}$.

Melanized fungi and lichens are colonizing extreme environments such as Arctic and Antarctic regions, including high altitude terrains. These specific regions are characterized by a combination of dry, cold, oligothophic extremes along with huge fluxes of UV radiation ${ }^{16,17}$. Therefore microcolonial fungi - and particularly C. antarcticus - have been suggested as eukaryotic models for studies on the habitability of Mars ${ }^{14}$ and the biological exploration of Mars ${ }^{1,18}$. Both, Mars-simulation experiments and the exposition of the fungus to outer space have shown that $C$. antarcticus is able to survive under Mars and space conditions in a good manner ${ }^{1,19}$. Also the green alga Stichococcus sp. and the lichenized fungus Acarospora sp. were shown to be able to survive Mars and space conditions $s^{20}$. 
Until now the cellular mechanisms underlying the resistance of MCF against harsh space and Mars conditions are not yet understood. At the moment there is limited information existing on a genomic sequences of MCF due to some obstacles occurring during DNA extraction and purification. Proteomics approach leads to understanding of the expression and regulation of the entire set of proteins which are directly related to biological functions ${ }^{21}$. Therefore two dimensional gel electrophoresis (2D) for protein profiling is carried out in this study in order to get a more precise impression of cellular and metabolic activity of these fungi under simulated Mars-like conditions. Three model organisms were chosen for the experiments, that were carried out in the Mars-simulation chamber in the Mars Simulation Facility (MSF) of the German Aerospace Centre (DLR, Berlin): (1) Cryomyces antarcticus represents a group of extremophilic fungi occurring in Antarctic dry deserts; (2) Knufia perforans is a mesophilic but highly stress tolerant fungus found in hot and arid environments and (3) Exophiala jeanselmei represents a rock inhabiting black yeast closely related to opportunistic pathogens in humans. A realistic simulation of the Martian climate was based on data provided by Mars-related missions $^{4,14}$.

\section{Results}

The results of the experiments showed (Table 1) that the number of expressed proteins has changed during the experiment in all fungi tested. After exposure to Mars-like conditions for 24 hours (day simulation) E. jeanselmei reduced the number of protein spots from 473 to 237 (Fig. 2). Protein spots representing proteins with high molecular weight $(<120 \mathrm{kDa})$ and basic pI-ranges of $<7$ were reduced in the number. From 24 hours to 4 days the number of proteins increased to 359 spots by expressing large proteins with basic $\mathrm{pH}$. And after incubation for 7 days the number of protein spots reached nearly the initial spot number of 470 . Within the protein profiles no significant changes of the patterns were observed; nearly all the spots were matched among the gels of different conditions, thus indicating there was no expression of new proteins after 24 hours (day simulation) or 4/7 days exposure. After 7 days the pattern and number of proteins resembles the cellular state at the starting point (the biomass from normal conditions) of the experiment, which indicated that no novel or stress-related proteins were expressed.

Also in $K$. perforans the number of proteins decreased after 24 hours before increasing during the following days of the experiment: after exposure for 24 hours (day simulation) the number of protein spots decreased significantly from 634 to 264 spots. The reduced proteins were of a large size (with the molecular weight of above $120 \mathrm{kDa}$ and basic pI-ranges of 7 to 9 ). After 4 days of

Table 1 | Number of protein spots detected in the 2D gels of the analyzed samples at each exposure condition. Opt-optimal laboratory conditions (normal conditions) at which fungi were grown for 30 days at temperature $20^{\circ} \mathrm{C}$ for $E$. jeanselmei and $K$. perforans and $15^{\circ} \mathrm{C}$ and for $C$. antarcticus. 24 hours-(D/N) - samples were exposed to Mars-simulated conditions for 24 hours with day/ night simulation respectively. 4/7 days- samples were exposed to Mars-simulated conditions for 4 and 7 days respectively. Blank cells $(-)$ indicate that the protein concentration was too low for $2 \mathrm{DE}$ analysis

Number of spots at each exposure condition

\begin{tabular}{lccccc}
\cline { 2 - 6 } Strain & Opt & $24 \mathrm{~h}-\mathrm{D}$ & $24 \mathrm{~h}-\mathrm{N}$ & 4 days & 7 days \\
\hline E. jeanselmei & 473 & 237 & - & 359 & 470 \\
K. perforans & 624 & 264 & - & 286 & 328 \\
C. antarcticus & 406 & 93 & 97 & - & - \\
\hline
\end{tabular}

treatment 286 protein spots were detected and after 7 days the protein number increased to 328 . The induction of new proteins was not detected in this fungus; however, many proteins were down-regulated and could not be visualized by silver-staining (Fig. 3). Protein extraction of E. jeanselmei and K. perforans for samples from night simulation was not successful and therefore the following $2 \mathrm{D}$ analysis could not be performed.

In C. antarcticus 406 spots were detected in the biomass from normal conditions before the start of the Mars-simulation treatment. After incubation for 24 hours at day and night simulation only 93 and 97 spots respectively were detected. There were no new protein spots appeared on the 2D gel patterns but over-expression of several proteins was observed (Fig. 4). Unfortunately, protein concentration of this fungus after 4 and 7 days of exposure to simulated Mars-like conditions was too low to perform further proteomic analyses.

After re-inoculation and incubation for 2 weeks at room temperature the increase of biomass (what is indicating growth of all the tested organisms) was observed. The biomass growth of all the tested strains manifested reproduction ability and survival for all fungal species after Mars-simulated treatments. The biomass, which used for the experiment was limited by the size of experimental chamber (Fig. 5). As it was mentioned in Materials and Methods section the extraction protocol was adapted to get sufficient protein amounts from those precious biomass samples. The analytical runs by $2 \mathrm{DE}$ was accomplished successfully for almost all the samples, however the amounts of the protein rather low to allow subsequent protein identification by proteomic approaches.

\section{Discussion}

The investigations of the microorganisms exposed to outer space and planetary simulated conditions support and enhance our understanding of basic biological mechanisms, such as biological effects caused by the radiation field in space and survival factors in the upper boundary of Earth's biosphere. Moreover the likelihood of interplanetary transport of microorganisms via meteorites, the use of microorganisms in bioregenerative life support systems, the monitoring, characterization and control of spacecraft microflora and associated microbial crew health are under concern ${ }^{6}$. Another aspect of space biological research is the investigation of the responses of microorganisms to simulated Mars-like conditions and their evaluation as potential forward contamination risks in the context of planetary protection $^{22}$.

The fungal abilities to withstand harsh outer space conditions and tendency to contaminate spacecrafts are of high importance due to: (1) some of the fungi are potential human pathogens and this could possess certain danger for the well-being of the crew in long-distant space journeys and (2) fungi have strong enzymatic systems and secrete various metabolites which can cause degradation of structural materials ${ }^{8,23}$. In their natural environment black microcolonial fungi from extreme environments are exposed to periods of temporary saturation with water vapor and temporary dryness. Although black microcolonial fungi, some lichens $\mathrm{s}^{4,14,19,23,24}$, bacteria and cyanobacteria ${ }^{25}$ were proven to survive Martian and outer space conditions ${ }^{1,19}$, it was never investigated on molecular level which cellular processes are responsible for this remarkable resistance.

The results of this study are the first approach to obtain a better understanding of survival mechanisms of MCF under Mars-like conditions. Although the experiments did not allow us to extract enough protein amounts for the identification of single protein spots (due to technical reasons allowing only very low amounts of the biomass to be placed inside the Mars simulation chamber), the results give some astonishing insights into ecology of MCF. The most important results of the study are:

The investigated fungi strains showed metabolic activity in close to anaerobic conditions during exposure to Mars-like conditions with a final exposure time of about 4 days in the first experiment and 7 days 
temperature and rel. humidity profile (pressure ca. $7 \mathrm{hPa}, 95 \% \mathrm{CO}_{2}, 5 \%$ Air)
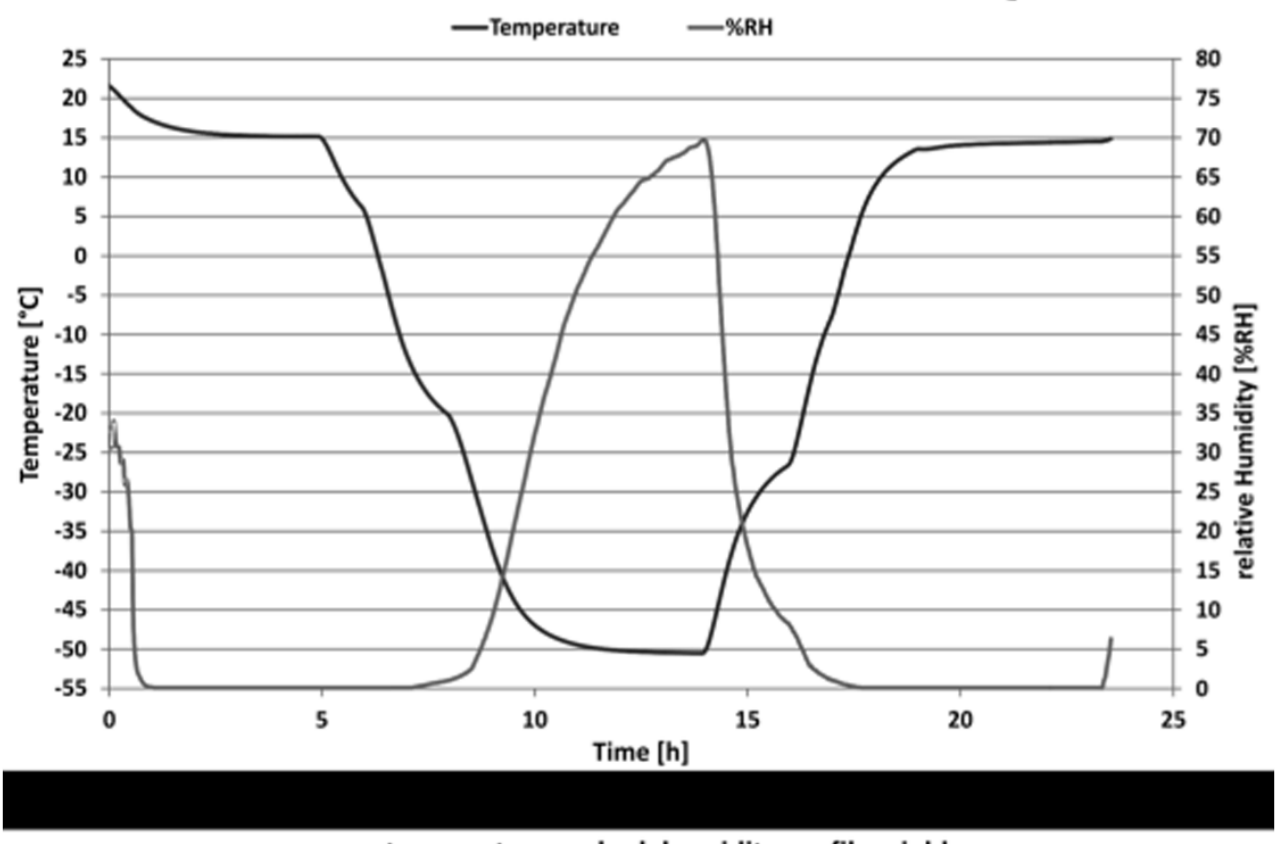

temperature and rel. humidity profile, yield

(pressure ca. $7 \mathrm{hPa}$; 95\% CO2; 5\%Air)

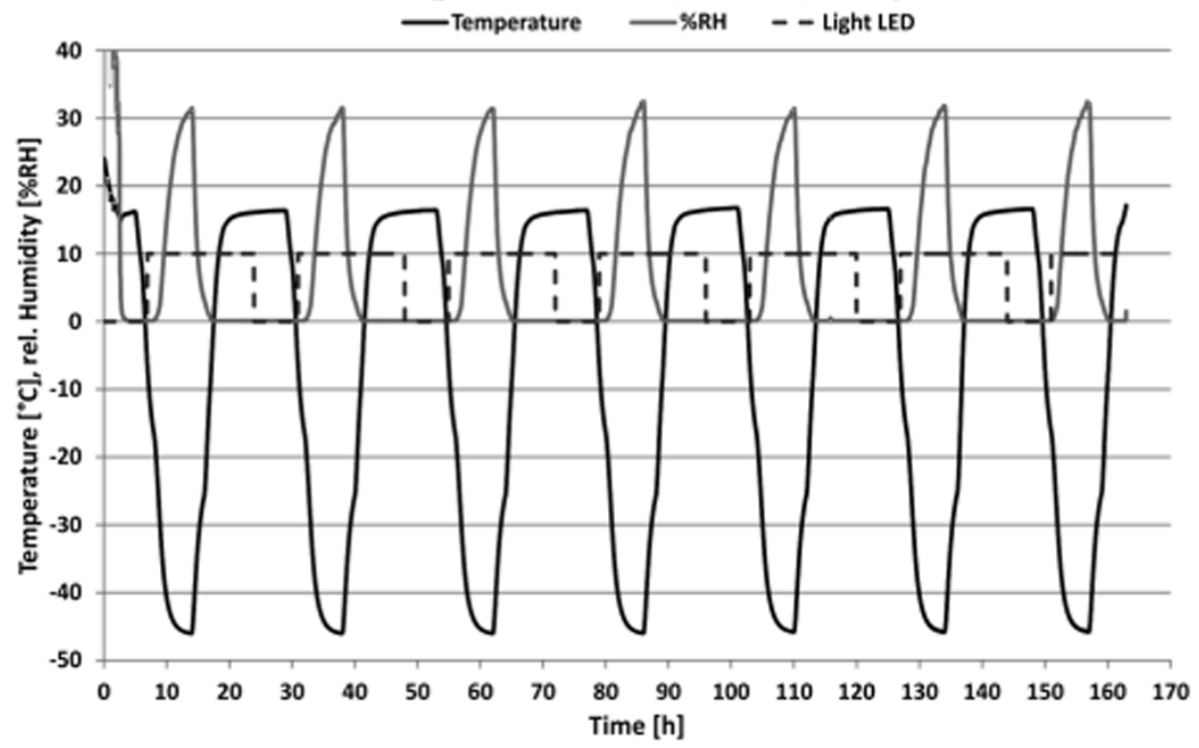

Figure 1 | An example over 24 hours and 7 days of the repetitive 'Mars-like' diurnal profile of temperature (circle curve) and humidity (smooth curve) in the experimental chamber. Temperature and relative humidity were measured above the sample (pressure approximately $7 \mathrm{hPa} ; 95 \% \mathrm{CO}_{2}, 5 \%$ Air). (A): Results of 24 hours samples exposure to Mars-like conditions (night simulation). (B): Results of 7 day samples exposure to Mars-like conditions (day simulation).

in the second experiment. Although there was a significant decrease of the number of protein spots during the first 24 hours, the fungi seem to recover and gain the initial metabolic state after 7 days of the exposure. These results are in accordance with what was observed earlier by Zakharova and collegues ${ }^{26}$, when fungi were desiccated to the constant weight and a decrease of proteins was observed in $C$. antarcticus whereas $K$. perforans and E. jeanselmei reacted by expression of new proteins, possibly representing protective proteins. During the following increase of relative humidity fungi did never gain a fully rehydrated state but they gained the original protein pattern after one hour of rehydration. The results of the Mars simulation experiments confirm the hypothesis that the fungi are able to be metabolic active with minimum amount of water and that their proteins have special conformations working with minimum water content ${ }^{22,26}$.

The fungi do not show the signs of stress reaction during the experiment. Previous studies have also shown that $C$. antarcticus does not react to temperature stress or by desiccation through production of novel proteins ${ }^{26,27}$. However, for E. jeanselmei and for $K$. perforans it was shown that they express proteins which could be protein chaperons or the so-called heat shock proteins ${ }^{26,27}$. In case of the Mars simulation none of the fungi showed such signals of stressresponse although they seem to be active when exposed to Marssimulated conditions.

The results of our study suggest that MCF seem to be not significantly stressed by Mars-like conditions, which are a combination of 
pI

3
pI

$10 \quad 3$

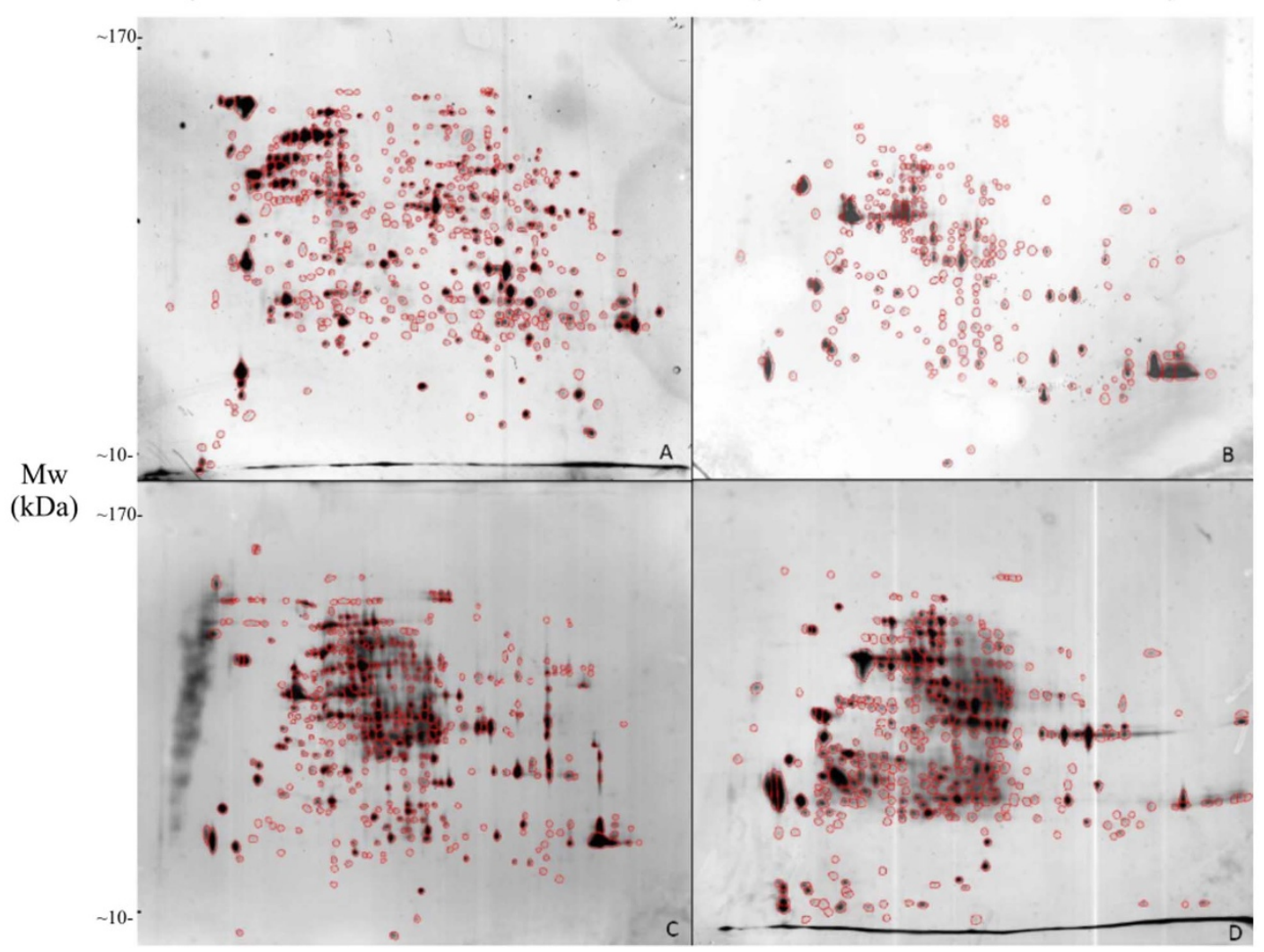

Figure 2 2D gel patterns obtained after exposure of Exophiala jeanselmei. (A): sample from optimal conditions. (B): sample was exposed to Marssimulated conditions for 24 hours with day simulation. (C): sample was exposed to Mars-simulated conditions for 4 days with day and night simulation. (D): sample was exposed to Mars-simulated conditions for 7 days with day and night simulation.

temperature extremes, pressure, dryness and radiation. The reason for that could be that the fungi have a basic set of stress resistant proteins ${ }^{21,26,27}$ and high doses of radiation enhance their growth capacity instead of damaging their cellular components. It was reported that the environments with high radiation, resulting from human activities, such as damaged reactor at Chernobyl and reactor cooling pool-water ${ }^{28,29}$ are habitats for black yeasts and MCF and that "melanizes fungal cells manifested increased growth after exposure to ionizing radiation"8. Analyzing melanized fungal species which were found in Chernobyl reactor and in the reactor cooling pool water showed that high fluxes of radiation selected for highly radio-resistant types of microorganisms, showed increased catalase and nuclease activities $^{28,29}$.

The results achieved from our study led to the conclusion that black microcolonial fungi can survive in Mars environment.

Further investigations are needed to characterize the present proteins and their functions. In other distantly related fungi strains some proteins are discovered, which might play a key role in stress-resistance to different environmental stresses. For instance the results obtained by Gocheva and collegues ${ }^{30}$ demonstrate that the growth at low temperatures does clearly induce oxidative stress events. Antarctic strains (Penicillium spp.) demonstrated a marked rise in activities of protective enzymes such as superoxide dismutase and catalase at decreasing temperatures. Low-temperature resistance is partially associated with enhanced scavenging systems ${ }^{30}$. Also it is known that protein carbonyls are biomarkers of protein oxidation followed by temperature stress ${ }^{31}$. The protein AoSO prevents excessive cytoplasmic leakage upon hyphal injury by accumulating at the septal pore, moreover in response to various stresses (low and high temperature; extreme acidic and alkaline $\mathrm{pH}$; nitrogen and carbon deplation $^{32}$ ). The protein Ipf2431 was discovered being important under several stress-induced proteins in fungus Cryptoccocus neofor$a n s^{33}$. Heterotrimeric $\mathrm{G} \alpha$ protein Pgal plays a central role in the regulation of the whole growth-developmental program of Penicillium chrysogenum. This protein also plays important role in germination (mediating carbon source sensing); absence of Pgal increases resistance to thermal, oxidative and osmotic stress ${ }^{34}$. According to Deegenaars and collegues, a $110 \mathrm{kDa}$ proteins play a role in stress tolerance in psychrophilic yeast, similar to that of HSP 104 in mesophilic species ${ }^{35}$. A described transcription factor PMsn2 in Beauveria bassiana and Metarhizium robertsii is important in tolerance to hyperosmolarity, oxidation, carbendazim, cell wall perturbing, high temperature and UV-B radiation ${ }^{36}$. The results of our study, however, suggest that stress-related protein machinery of $\mathrm{MCF}$ is more complex compared to other fungi strains and there are a number of highly abundant proteins needed for the survival in Mars-simulated conditions.

We can conclude that an unknown metabolic pathway might be discovered, which enables the fungi to live in a quasi-anaerobic Mars-like environment.

\section{Methods}

The biological samples as model organisms. The organisms used for this study were: (1) Exophiala jeanselmei MA 2853, a rock inhabiting black yeast closely related to opportunistic pathogens in humans; (2) Knufia perforans MA 1299, a mesophilic but highly stress tolerant fungus found in hot and dry environments, like the Mediterranean; (3) Cryomyces antarcticus MA 5682, an extremophilic fungus from Antarctica. The strains were obtained from the ACBR culture collection (Austrian Center of Biological Resources and Applied Mycology, www.acbr-database.at).

Inoculi were prepared as cell suspensions and drop-inoculated onto sterilized cellophane membranes (Model 583 gel dryer Backing. Catalog \#1650963, Bio-Rad), which were placed on the surface of $2 \%$ malt-extract agar (MEA, Applichem GmbH, 
$3<\mathrm{pI}$

3

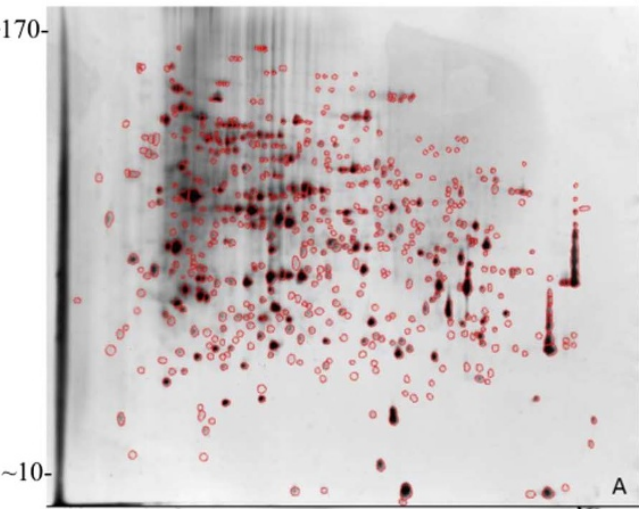

$\mathrm{Mw}$

$(\mathrm{kDa})$

$\sim 170$ -
pI

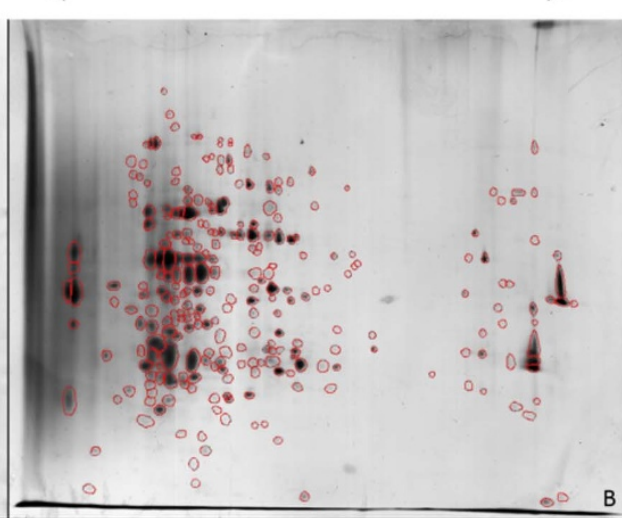

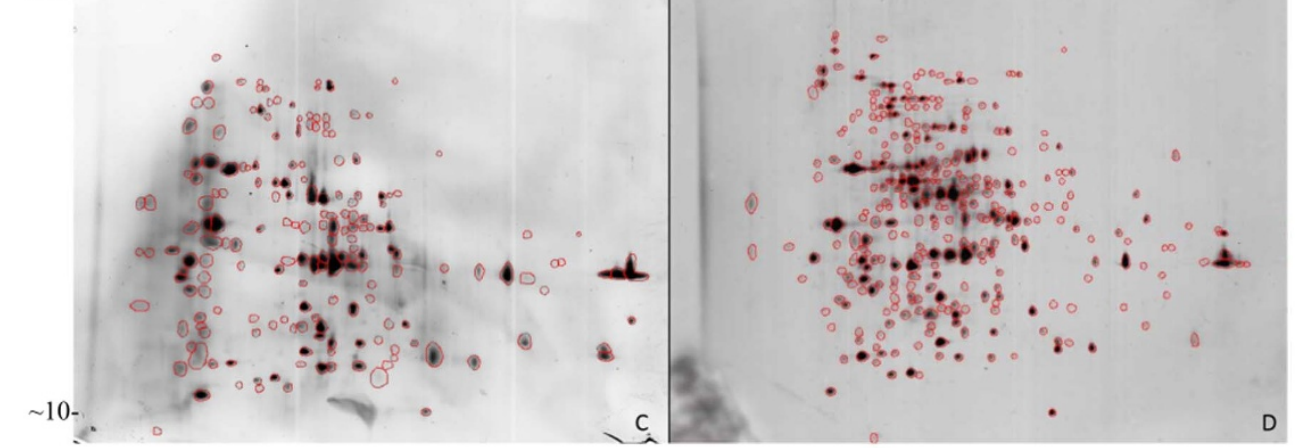

Figure 3 2D gel patterns obtained after exposure of Knufia perforans: (A): sample from optimal conditions. (B): sample was exposed to Marssimulated conditions for 24 hours with day simulation. (C): sample was exposed to Mars-simulated conditions for 4 days with day and night simulation. (D): sample was exposed to Mars-simulated conditions for 7 days with day and night simulation.

Darmstadt, Germany). Fungi were grown at normal conditions: $20^{\circ} \mathrm{C}(293 \mathrm{~K})$ for $E$. jeanselmei and $\mathrm{K}$. perforans and $15^{\circ} \mathrm{C}(288 \mathrm{~K})$ and for C. antarcticus for 30 days. For samples from normal conditions the biomass was harvested by scratching the material from the plates using a scalpel, transferred into a sterile tube, then immediately frozen in liquid nitrogen and stored at $-80^{\circ} \mathrm{C}(193 \mathrm{~K})$ for further analysis. Other samples were prepared as follows: round segments approximately three $\mathrm{cm}$ diameter from the cellophane membranes with well grown fungal colonies were cut out and transferred into empty three $\mathrm{cm}$ diameter dishes and then placed into the Mars simulation chamber.

Mars-simulation. The experiment was carried out in the Mars Simulation Facility (MSF) at the Institute of Planetary Research of the German Aerospace Center (DLR) Berlin. The MSF simulates Mars-like atmospheric conditions and is used to perform laboratory experiments with controlled time-profiles. The main part of the MSF is an "experimental chamber" (EC) located in a temperature test chamber. The experiments were performed in EC, which can be cooled, evacuated and filled with defined gas mixture and humidity in a controlled manner. The MSF, its performance and typical experiments are described by Lorek and $\mathrm{Koncz}^{37}$.

For the experiment, two gases $\left(\mathrm{CO}_{2}\right.$ and air) were mixed and humidified. A gas volume flow of 10 liters per hour (approximately Standard Ambient Temperature $25^{\circ} \mathrm{C}(298 \mathrm{~K})$ and Pressure $\left.101325 \mathrm{~Pa}\right)$ of the resulting gas mixture $\left(\mathrm{CO}_{2} 95 \% /\right.$ volume, air $5 \%$ /volume $\left(\mathrm{N}_{2} 4 \%\right.$ /volume and $\mathrm{O}_{2} 1 \%$ /volume $)$ was used to pass through the EC. Thus the humidity of the mixture inside the chamber, which was directly provided, corresponded to a partial water vapor pressure of about $3 \mathrm{~Pa}$, which is the average closed to the $2.7 \mathrm{~Pa}$ vapor pressure in-situ measured in polar regions on Mars ${ }^{4,38}$. The pressure inside the experiment chamber was between $1000 \mathrm{~Pa}$ (at the starting time) and $700 \mathrm{~Pa}$ (main part until the end of the experiment). Complete Xenon-lamp radiation spectra between $200 \mathrm{~nm}$ and $2200 \mathrm{~nm}$ was used. The Xenonlamp was switched on and off every day to stimulate the diurnal cycle of the sun. The day simulation was made by allowing light for 16 hours (for 8 hours light was off); night simulation for testing the effect of Mars-like atmospheric conditions without radiation was produced by covering the samples with aluminium foil. An applied
pI 3

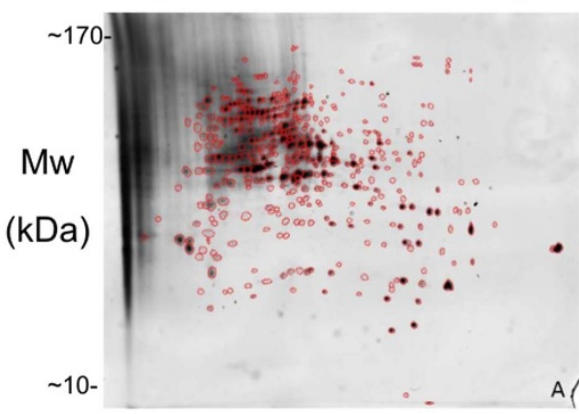

pI

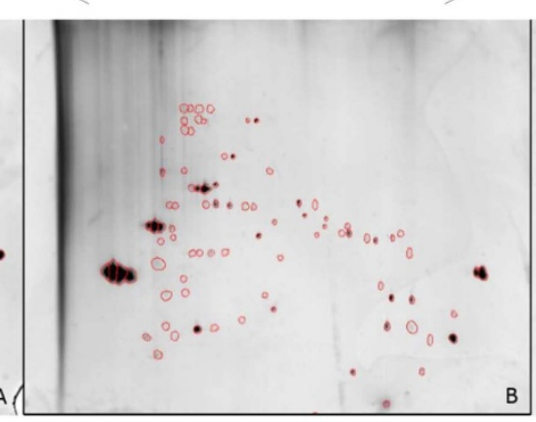

$\mathrm{pI}$

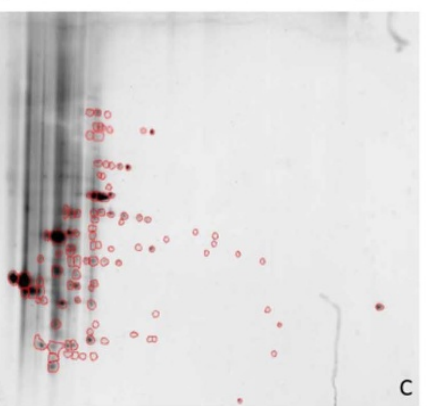

Figure 4 2D gel patterns obtained after exposure of Cryomyces antarcticus. (A): sample from optimal conditions. (B): sample was exposed to Marssimulated conditions for 24 hours with day simulation. (C): sample was exposed to Mars-simulated conditions for 24 hours with night simulation. 


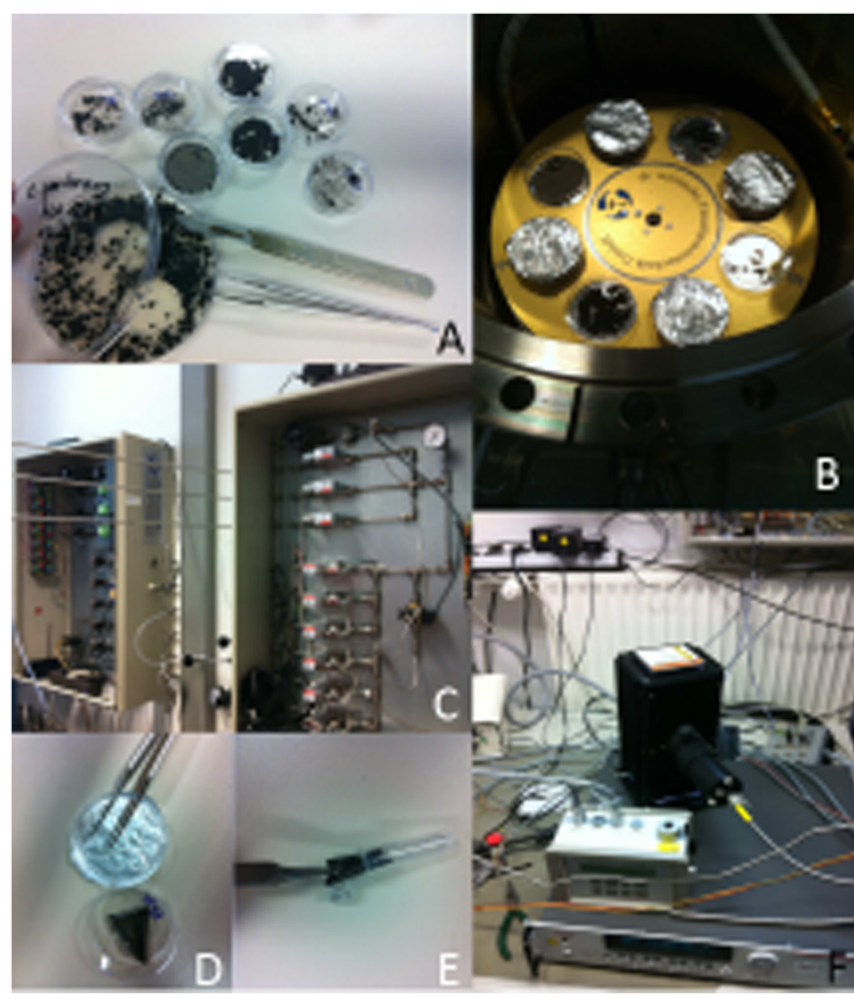

Figure 5 | Experimental flow. (A): Sample preparation for loading into experimental chamber. (B): samples prepared for the exposure with day and night (the lid of the plate is covered with aluminium foil, enabling prevention of UV radiation exposure). (C): gas-mixing system. (D, E): samples after exposure to Martian simulated conditions. (F): Mini-Pam (photosynthetic activity), Xenon-Lamp housing and measurement equipment.

simulation was used as follows: for samples treated for 24 hours (day and night simulation) was $153 \mathrm{~kJ} / \mathrm{m}^{2}$; for samples treated for 4 days $598.8 \mathrm{~kJ} / \mathrm{m}^{2}$ and for the samples treated for 7 days $1131 \mathrm{~kJ} / \mathrm{m}^{2}$. All the parameters are summarized in the Table 2.

All relevant experimental parameters and data were PC-controlled and logged in by software programs, which were LabView based.

For each experiment maximum eight of three $\mathrm{cm}$ diameter plates were placed on a rotation disc of the experimental chamber. Thus samples were placed on a sample holder which was exposed to the simulated Mars-like solar radiation provided by the Xenon lamp which is realizing the Mars-like surface conditions. The temperature varied in a diurnal cycle between $-55^{\circ} \mathrm{C}\left(218^{\circ} \mathrm{K}\right)$ at night and $15^{\circ} \mathrm{C}\left(288^{\circ} \mathrm{K}\right)$ at daytime. The temperature and humidity inside the chamber were measured by three platinum resistance thermometers Pt100 (IST AG) which were arranged inside the chamber at the holder, two Pt100 temperature sensors and one capacitive humidity sensor. The humidity sensor and the Pt100 were fixed close to the biological samples at a distance between 1 and $2 \mathrm{~cm}$. The second Pt100 was fixed in the middle of the chamber. Those controlled thermo-physical parameters such as humidity, gas mixture, temperature, pressure, and in addition the SOL-irradiation (including UVirradiation with Xenon lamp via fiber inside the experimental chamber) allowed the simulation of Mars-like conditions (Fig. 1). Experimental scheme was as follows:

(1) samples were exposed for 24 hours with or without UV light (day/night simulation)as described above

(2) samples were exposed to treatments with a final exposure time of 4 days

(3) samples were exposed to treatments with a final exposure time of 7 days

After each experiment a small inoculum was transferred onto a Petri dish containing $2 \%$ MEA media to check the viability of the fungi. Remaining biomass was immediately frozen in liquid nitrogen for 2D gel electrophoresis.

Protein extraction and 2D gel protein profiling. Extraction of whole biomass proteins and 2D gel electrophoresis was based on a protocol, which was specially optimized for black fungi biomass ${ }^{39}$ with some modifications. As it was mentioned before, the chamber allows using very limited amount of the samples; the obtained biomass was rare and precious therefore some modifications (described below) in the protocol were made which luckily allowed us to extract proteins from extreme low biomass quantities. Prior to the extraction the biomass was disrupted in liquid nitrogen by mortar. The powder-like biomass was washed in saline solution $(\mathrm{NaCl}$
Table 2 | Mars-simulated conditions used for the experiments

Parameter

Values

Gas mixing rates

Gas humidity

Volume flow

Pressure inside the chamber

Radiation spectra

(Xenon-lamp)

Simulation

Temperature

Exposure time with corresponding dose

\author{
$\mathrm{CO}_{2} 95 \% /$ volume, air $5 \% /$ volume \\ ( $\mathrm{N}_{2} 4 \% /$ volume and $\mathrm{O}_{2} 1 \%$ /volume) \\ $3 \mathrm{~Pa}$ \\ 10 liters/hour* \\ $1000 * *-700 * * * \mathrm{~Pa}$
}

$200 \mathrm{~nm}$ and $2200 \mathrm{~nm}$

day simulation for 24 hours: light on for

16 hours and light off for 8 hours

night simulation for 24 hours: light off

Was varying in a diurnal cycle between: day simulation: $15^{\circ} \mathrm{C}\left(288^{\circ} \mathrm{K}\right)$

night simulation: $-55^{\circ} \mathrm{C}\left(218^{\circ} \mathrm{K}\right)$

24 hours(day and night simulation): $153 \mathrm{~kJ} / \mathrm{m}^{2}$; 4 days simulation: $598.8 \mathrm{~kJ} / \mathrm{m}^{2}$

7 days simulation $1131 \mathrm{~kJ} / \mathrm{m}^{2}$

*at approximately Standard Ambient Temperature and Pressure $101325 \mathrm{~Pa}$ and $25^{\circ} \mathrm{C}$.

**at the starting time and ***main part until the end of the experiment

$0.9 \%)$ and proceeded as given in the basic protocol ${ }^{39}$. After cell disruption the lysate was transferred into $15 \mathrm{ml}$ polypropylene centrifuge tube and $3 \mathrm{ml}$ of Tris-buffered phenol solution, pH 8.0 (Sigma-Aldrich, Steinheim, Germany) was added and mixed for $40 \mathrm{~min}$ at room temperature. The remaining steps were performed according to the basic protocol $^{39}$. Protein determination was carried out using Bradford Protein Assay.

The Bradford protein Assay ${ }^{40}$ was performed to determine the concentration of protein in fungal extracts. Reactions were carried out in microtiter plates according to the manufacturer instructions. A standard curve was established using serial dilutions from $0.8 \mu \mathrm{g} \mathrm{ml}^{-1}$ to $100 \mu \mathrm{g} \mathrm{ml}^{-1}$ of bovine serum albumin (BSA). The resulting optical density (OD) at $595 \mathrm{~nm}$ was analyzed with a plate reader (Magellan; Tecan Austria, Grödig, Austria). All experiments were carried out in triplicate. For each gel $20 \mu \mathrm{g}$ of proteins were applied. IEF separation was performed using $13 \mathrm{~cm}$ strips pH 3-10NL. For each condition 2D gels were made in triplicate. Visualization of protein spots was made by a high sensitive mass spectrometric compatible silver staining ${ }^{41}$. The gels were fixed in 50\% (v/v) methanol and $5 \%(\mathrm{v} / \mathrm{v})$ acetic acid for $20 \mathrm{~min}$, followed by washing in $50 \%(\mathrm{v} / \mathrm{v})$ methanol for $10 \mathrm{~min}$ and then left in MilliQ water (Millipore, MA, USA) overnight at $4{ }^{\circ} \mathrm{C}(277 \mathrm{~K})$ with gentle agitation. Thereafter, the $2 \mathrm{D}$ gels were sensitized using a $0.02 \%(\mathrm{w} / \mathrm{v})$ sodium thiosulphate solution for $1 \mathrm{~min}$ followed by incubation in $0.04 \%(\mathrm{v} / \mathrm{v})$ formalin and $2 \%(\mathrm{w} / \mathrm{v})$ sodium carbonate solution until the desirable intensity of staining was achieved. All the washing solutions were prepared in MilliQ water (Millipore, MA, USA).

After staining the gels were scanned in TIFF 16 bit format; for each sample (normal condition, 24 hours (day/night simulation) and exposure for $4 / 7$ days); the 3 gels were matched by warping (Image Master 2D Platinum version 5.0, Amersham Biosciences, Swiss Institute of Bioinformatics, Geneva, Switzerland) and the sum of all spots which were present at least in two gels was taken into account for the protein pattern analysis.

1. Onofri, S. et al. Resistance of Antarctic black fungi and cryptoendolithic communities to simulated space and Mars conditions. Stud. Mycol. 61, 99-109 (2008).

2. Billi, D. Subcellular integrities in Chroococcidiopsis sp. CCMEE 029 survivors after prolonged desiccation revealed by molecular probes and genome stability assays. Extremophiles. 13, 49-57 (2009).

3. Cavicchioli, R. Extremophiles and the search for extraterrestrial life. Astrobiology. 2, 281-292 (2002).

4. de Vera, J.-P. et al. Survival potential and photosynthetic activity of lichens under Mars-like conditions: a laboratory study. Astrobiology. 10, 215-227 (2010).

5. de Vera, J.-P. Lichens as survivors in space and on Mars. Fungal Ecol. 5, 472-479 (2012).

6. Horneck, G., Klaus, D. M. \& Mancinelli, R. L. Space Microbiology. Microbiol. Mol. Biol. Rev. 74, 121-156 (2010)

7. Dighton, J., Tugay, T. \& Zhdanova, N. Fungi and ionizing radiation from radionuclides. FEMS Microbiol. Lett. 281, 109-120 (2008).

8. Dadachova, E. \& Casadevall, A. Ionizing radiation: how fungi cope, adapt, and exploit with the help of melanin. Curr. Opin. Microbiol. 11, 525-531 (2008).

9. Hulot, G. \& Gallet, Y. Do superchrons occur without any palaeomagnetic warning? Earth and Planetary Science Letters. 210, 191-201 (2003).

10. Rivkina, E. M., Friedmann, E. I., McKay, C. P. \& Gilichninsky, D. A. Metabolic activity of permafrost bacteria below the freezing point. Appl. Environ. Microbiol. 66, 3230-3233 (2000). 
11. Stoker, C. R. et al. Habitability of the Phoenix landing site. J. Geophys. Res. 115: E00E20, 24 pp. DOI: 10.1029/2009JE003421 (2010).

12. Morozova, D., Möhlmann, D. \& Wagner, D. Survival of methanogenic archaea from Siberian permafrost under simulated Martian thermal conditions. Orig. Life Ecol. Biosph. 37, 189-200 (2007).

13. McKay, C. P. et al. The icebreaker life mission to Mars: a search for biomolecular evidence for life. Astrobiology 13, 334-353 (2013).

14. de Vera, J.-P. et al. Adaptation of an Antarctic lichen to Martian niche conditions can occur within 34 days. PSS. (in press) (2013).

15. Möhlmann, D. Adsorption water-related potential chemical and biological processes in the upper Martian surface. Astrobiology. 5, 770-777 (2005).

16. Robinson, C. H. Cold adaptation in Arctic and Antarctic fungi. New Phytologist. 151, 341-353 (2001)

17. Sterflinger, K., de Hoog, G. S. \& Haase, G. Phylogeny and ecology of meristematic ascomycetes. Stud. Mycol. 43, 5-22 (1999).

18. Onofri, S., Selbmann, L. \& Pagano, S. Antarctic microfungi as models for exobiology. Planetary Space Sci. 52, 229-237 (2004).

19. Onofri, S. et al. Survival of rock-colonizing organisms after 1.5 years in outer space. Astrobiology. 12, 508-516 (2012).

20. Scalzi, G. et al. LIFE Experiment: isolation of Cryptoendolithic organisms from Antarctic colonized sandstone exposed to space and simulated Mars conditions on the international space station. Orig. Life Evol.Biosph. 42, 253-262 (2012).

21. Marzban, G., Tesei, D. \& Sterflinger, K. A review beyond borders: proteomics of microcolonial black fungi and black yeast. Nat. Sci. 5, 640-645 (2013).

22. Moeller, R., Schuerger, A. C., Reitz, G. \& Nicholson, W. L. Protective role of spore structural components in determining Bacillus sublitis spore resistance to simulated Mars surface conditions. Appl. Environ. Microbiol. 87, 8849-8853 (2012).

23. Novikova, N. D. Review of the knowledge of microbial contamination of the Russian manned spacecraft. Microb. Ecol. 47, 127-132 (2004).

24. de la Torre, R. et al. Likelihood of interplanetary transfer of rock-inhabiting microbial communities: results from the space experiment Lithopanspermia Icarus. 208, 735-748 (2010).

25. Stöffler, D. et al. Experimental evidence for the potential impact ejection of viable microorganisms from Mars and Mars-like planets. Icarus 186, 585-588 (2007).

26. Zakharova, K. et al. Microcolonial fungi on rocks: a life in constant drought? Mycopatologia 175, 537-547 (2013).

27. Tesei, D. et al. Alteration of protein patterns in black rock inhabiting fungi as a response to different temperatures. Fungal Biol. 116, 932-940 (2012).

28. Mironenko, N. V., Alekhina, I. A., Zhdanova, N. N. \& Bulat, S. A. Intraspecific variation in Gamma-radiation resistance and genomic structure in the filamentous fungus Alternaria alternate: a case study of strains inhabiting Chernobyl reactor No.4. Ecotoxicol. Environ. Safety. 45, 177-187 (2000).

29. Robertson, K. L. et al. Adaptation of the Black yeast Wangiella dermatitidis to ionizing Radiation: Molecular and Cellular Mechanisms. PLoS ONE 7 (2012).

30. Gocheva, Y. G. et al. Cell response of Antarctic and temperate strains of Penicillium spp. to different growth temperature. Mycol.l Res. 110, 1347-1354 (2006).

31. Li, Q., Harvey, L. M. \& McNeil, B. The effects of elevated process temperature on the protein carbonyls in the filamentous fungus, Aspergillus niger B1-D. Process Biochem. 43, 877-881 (2008).

32. Maruyama, J., Escaño, C. S. \& Kitamoto, K. AoSO protein accumulates at the septal pore in response to various stresses in the filamentous fungus Aspergillus oryzae. Biochem. Biophys. Res. Commun. 391, 868-873 (2010).

33. Kroll, K., Pähtz, V. \& Kniemeyer, O. Elucidating the fungal stress response by proteomics. J. proteomics (in press) (2013).

34. García Rico, R. O., Martín, J. F. \& Fierro, F. Heterotrimeric G $\alpha$ protein Pgal from Penicilluim chrysogenum triggers germination in response to carbon source and affects negatively resistance to different stress conditions. Fungal Genet. Biol. 48, 641-649 (2011).
35. Deegenaars, M. L. \& Watson, K. Stress proteins and stress tolerance in an Antarctic, psychrophilic yeast, Candida psychrophiala. FEMS Microbiol. Lett. 151, 191-196 (1997)

36. Liu, Q., Ying, S.-H., Li, J.-G., Tian, C. G. \& Feng, M.-G. Insight into the transcriptional regulation of Msn2 required for conidiation, multi-stress responses and virulence of two entomopathogenic fungi. Fungal Genet. Biol. 54, $42-51$ (2013).

37. Lorek, A. \& Koncz, A. [Simulation and measurement of extraterrestrial conditions for experiments on habitability with respect to mars]. Habitability of Other Planets and Satellites [de Vera, J.-P. \& Seckbach, J. (ed.)] [145-162] (Springer Netherlands, Dordrecht, 2013).

38. Zent, A. P. et al. Initial results from the thermal and electrical conductivity probe (TECP) on Phoenix. J. Geophys. Res. 115; DOI:10.1029/2009JE003420 (2010).

39. Isola, D. et al. Establishment of sample preparation and 2-DE procedure for protein expression profiling of black fungi. Fungal Biol. 115, 971-977 (2011).

40. Bradford, M. M. A rapid and sensitive method for the quantitation of microgram quantities of protein utilizing the principle of protein-dye binding. Anal. Biochem. 72, 248-254 (1976).

41. Shevchenko, A., Wilm, M., Vorm, O. \& Mann, M. Mass spectrometric sequencing of proteins from silver stained polyacrylamide gels. Anal. Chem. 68, 850-858 (1996).

\section{Acknowledgments}

We kindly acknowledge the Austrian science foundation FWF (grant No. P 24206-B16) and thank for the financial support. This research was also supported by the Helmholtz Association through the Helmholtz-Alliance "Planetary Evolution and Life". We also thank the VIBT-equipment GmbH for supporting the BOKU Extremophile Center. Silvano Onofri was the first who isolated the strain Cryomyces antarcticus from Arctic deserts and he kindly provided the strain for our research on stress adaptation.

\section{Author contributions}

K.S. conceived the project, she is the project-leader of the FWF project grant; she established the collaboration with J.-P.dV. K.S., J.-P.dV. and K.Z. made an experimental design. J.-P.dV. provided access to the facility of German Aerospace Center (DLR); J.-P.dV. and A.L. supervised the laboratory work at DLR; provided the data for 'Mars simulation' subunit in 'Materials and Methods' chapter; proof-read the manuscript. K.Z. performed the laboratory work (exposure of the samples to Mars-simulated conditions) at DLR; laboratory work and computer analysis (proteomics) at University of Natural Resources and Life Sciences, Vienna (BOKU); wrote the manuscript. G.M. and K.S. supervised the practical work in the laboratory of BOKU; proof-read the manuscript.

\section{Additional information}

Competing financial interests: The authors declare no competing financial interests.

How to cite this article: Zakharova, K., Marzban, G., de Vera, J.-P., Lorek, A. \& Sterflinger, K. Protein patterns of black fungi under simulated Mars-like conditions. Sci. Rep. 4, 5114; DOI:10.1038/srep05114 (2014)

This work is licensed under a Creative Commons Attribution-NonCommercialNoDerivs 3.0 Unported License. The images in this article are included in the article's Creative Commons license, unless indicated otherwise in the image credit; if the image is not included under the Creative Commons license, users will need to obtain permission from the license holder in order to reproduce the image. To view a copy of this license, visit http://creativecommons.org/licenses/by-nc-nd/3.0/ 